\title{
Assessment of Physical Health Status of Female Construction Workers of Kathua District, J\&K
}

\author{
Dr. Sarika Manhas (Asstt. Prof) \\ P.G. Department Of Home Science, University Of Jатти, Jammu, J\&K.
}

\begin{abstract}
The present study was conducted to assess the physical health status of female construction workers of Kathua District of $J \& K$. The core sample for the study comprised 120 female construction workers equally divided in two age group viz, 20-30 and 30-40 years. The selected construction workers were required to be performing construction activities for at least past 2 years. The tools used for the data collection were an interview schedule, C.M.I. health questionnaire and an observation checklist. Results reveal that majority of the sample female workers had moderate level of problems related to various health dimensions namely, eyes, musculo skeletal system, skin, and genitourinal tract. But at the same time had lower level of problems related to respiration, cardio vascular system, digestive tract and nervous system. Redness, pain, irritation and watery eyes were fairly common along with breathing problems and chest congestion. Digestion related problems including diarrhea, acidity and constipation; along with skin rashes and lesions were also noted. Muscular pains and joint aches were also frequently noted. Nervous system problems reported included feeling of dizziness, fainting spells, headaches and cold sweats. There was also low to moderate incidence of fatigue and moderate to high incidence of illness among the sample females. Statistically there was significant difference in the physical health of the two age groups. Comparatively women in the 30-40 years age group faced more problems in eyes, nervous system, genitourinal system and encountered more incidence of illness than the younger age group. Overall, the results highlight the poor health condition of female construction workers.
\end{abstract}

Key words: Female Construction workers, Physical health, Fatigue, Illness

\section{Introduction}

Construction sector is the world's largest industrial employer with 7\% of total world employment and $28 \%$ industrial employment. Construction activity is an integral part of a country's infrastructure and industrial development. In India, the construction sector is the largest employer of unorganized labour next to the agriculture sector. Around $16 \%$ of the India's working population depends on building construction for its livelihood. Indian construction labour force is estimated at 30 million people, of whom about half are women (Jhabvala and Kanbur, 2002).

In India construction is the third largest employer of women with 5.1\% of working women or 5.7 million being involved on construction sites (Lahiri, 2012). They clean the building sites, and serve the skilled men workers by carrying material and load and doing other task directed by men. The differentiation in work allotted to men and women on building sites occurs on the grounds of what is considered appropriate for men and women and not on the basis of the skill and capacity of the women to do work. Construction is one of the few industries where people can work their way to the top from the bottom level. But women in India are denied promotional opportunities in the construction sector. In the absence of mechanization of work many energy sapping tasks are assigned to women. Women labourers continue to be available as cheap labour and are largely considered as unskilled. However, women are rarely found in male-dominated skilled trades such as carpentry, masonry and electrical wiring (Jhabvala and Kanbur, 2002).

Construction work involves many occupational risks, such as work at heights, excavation work, lifting of materials and so on, which are specific to the sector. Thus, construction is often classified as a high risk industry as it has historically been plagued with much higher and unacceptable injury rates compared to other industries. Accidents at construction sites are identified as a major public health problem throughout the world, even though the number of fatal occupational accidents in the construction industry globally cannot be estimated due to paucity of data from many countries, yet it is reasonably estimated that at least 55, 000 fatalities occur at construction sites around the world every year. This means worldwide one fatal accident occurs in this sector approximately every 10 minutes (Dong, 2005). In developing countries like India these construction activities are carried out by unskilled labour forces at cheap rate. Occupational injuries and accidents among these workers are high due to illiteracy, poverty, lack of health and safety training and information on health hazards and risks at work place. Occupational hazards faced by these workers in a country like ours are higher than that faced in industrialized countries (Gurav, 2005 and Shah and Mehta, 2009). 
With this as background the present study was carried out to assess the physical health status of the female construction workers. The potential physical health implications of the construction activities on the sample women were evaluated.

\section{Research Methodology:}

Sample Description: The sample for the study comprised of female building construction workers in the age range of 20-40 years. For the present study those building construction worker were selected who were employed in the construction of buildings, residential houses etc for at least past one year. The construction workers selected were further divided into two equal sub divisions i.e. adults in the age group of 20-30 years and adults in the age group of 30-40 years respectively.

Sampling Technique: The sample was selected by a combination of random and snow ball sampling technique from various wards of Kathua District of J\&K state. Out of the 17 wards of Kathua, 06 were selected through lottery method as locale of the study. Then a survey of the selected geographic areas was carried out to identify a few construction sites where work was being conducted at the particular interval of time. From these construction sites female construction workers satisfying the sampling criteria were selected. Later, snow ball sampling technique was applied and the first set of construction workers led to subsequent sample units. The process of one set of sample leading to another continued until the desired sample size was obtained.

Tools used for Data collection:

(i) Interview Schedule: - An interview schedule was constructed to gather information related to family and work profile of construction workers. Also, their awareness of the risks involved with their jobs and safety precautions undertaken at work sites were noted.

(ii) Health questionnaire: Another tool used was C.M.I (Cornall medical index) Health questionnaire devised by Wig et al. Section A to L pertaining to physical distress was only used for data collection.

(iii) Checklist:- A self devised checklist with 51 items was prepared to record signs of any apparent health problems of workers. The severity of health problems was rated as: Clearly apparent, Less apparent, and not apparent at all.

\section{Results And Discussions}

The physical health profile of female construction workers was assessed in areas namely eyes, respiratory system, cardio-vascular system, digestive tract, musculo-skeltal system, skin, nervous system, fatigability, illness, miscellaneous diseases and habits.

$$
\text { 1. Eyes }
$$

Table 1

EYES

$20-30$ years $\quad 30-40$ years $\quad$ Total

\begin{tabular}{lllllll} 
Level of problem & $\mathbf{N}$ & $\mathbf{\%}$ & $\mathbf{N}$ & $\mathbf{\%}$ & $\mathbf{N}$ & $\mathbf{\%}$ \\
\hline No Problem & 03 & 5 & 03 & 5 & 6 & 5 \\
Low & 09 & 15 & 18 & 30 & 27 & 22.5 \\
Moderate & 27 & 45 & 29 & 48.3 & 56 & 46.6 \\
High & 10 & 16.6 & 21 & 35 & 31 & 25.8 \\
Total & 60 & 100 & 60 & 100 & 120 & 100 \\
\hline
\end{tabular}

$\chi 2=15.1^{*}$, Table Value $=7.81, \alpha=0.05$, * significant at $5 \%$ level.

Table 1 reveals that majority of the sample construction workers $(46.6 \%)$ had moderate level of problems related to eyes and $25.8 \%$ reported suffering from high level of eye problems. The common problem related to eyes was redness, pain, irritation and watery eyes. The females reported that when they worked for long hours the eyes pained and they felt stressed. Calculation of $\chi 2$ reveals that there was significant difference in the incidence of eye problems between the two age groups. As, $35 \%$ of 30-40 year olds had high incidence of eye problems compared to $16.6 \%$ of 20-30 years old. Overall, it was found that older female construction workers had more problems of eyes than the younger age group. 
Table 2

Respiratory System

20-30years 30-40 years $\quad$ Total

\begin{tabular}{lllllll} 
Level of problem & $\mathbf{N}$ & $\boldsymbol{\%}$ & $\mathbf{N}$ & $\boldsymbol{\%}$ & $\mathbf{n}$ & $\boldsymbol{\%}$ \\
\hline No Problem & 01 & 1.6 & 0 & 0 & 1 & 0.8 \\
Low & 42 & 70 & 36 & 60 & 78 \\
Moderate & 17 & 28.3 & 24 & 40 & 41 \\
High & 0 & 0 & 0 & 0 & 34 \\
Total & 60 & 100 & 60 & 100 & 0 \\
\hline
\end{tabular}

$\chi 2=2.12$, Table Value $=7.81, \alpha=0.05$, insignificant at $5 \%$ level

Table 2 enumerates that most $(65 \%)$ of the sample females had low level of respiration problems followed by $34 \%$ who had moderate levels of respiratory complications. None of the women complained of severe respiration problems and had never faced serious breathing problems and chest congestion. Calculation of $\chi 2$ reveals no significant differences in the respiratory problems of the two age groups.

\section{Cardiovascular System}

Table 3

Cardiovascular System

\begin{tabular}{|c|c|c|c|c|c|c|}
\hline \multirow[t]{2}{*}{ Level of problem } & \multicolumn{2}{|c|}{ 20-30 Years } & \multicolumn{2}{|c|}{ 30-40 years } & \multicolumn{2}{|c|}{ Total } \\
\hline & $\mathbf{n}$ & $\%$ & $\mathbf{n}$ & $\%$ & & $\%$ \\
\hline No Problem & 1 & 1.6 & 0 & 0 & 1 & 0.8 \\
\hline Low & 42 & 70 & 36 & 60 & 78 & 65 \\
\hline Moderate & 17 & 28.3 & 24 & 40 & 41 & 34 \\
\hline High & 0 & 0 & 0 & 0 & 0 & 0 \\
\hline Total & 60 & 100 & 60 & 100 & 120 & 100 \\
\hline
\end{tabular}

$\chi^{2}=2.2$, Table Value $=7.81, \alpha=0.05$, insignificant at $5 \%$ level.

Table 3 reveals that most $(65 \%)$ of the sample females had low level of cardiovascular problems, followed by $34 \%$ who had moderate levels of the problem. Calculation of $\chi \mathbf{2}$ reveals insignificant differences in the cardiovascular problems encountered by the two age groups. None of females in the two age group had high levels of these problems. Even though a very few of them had got themselves checked for blood pressure and heart functioning yet they sometimes complained of heart pain and uneasiness along with high pulse rate.

\section{Digestive Tract}

Table 4

Digestive Tract

\begin{tabular}{|c|c|c|c|c|c|c|}
\hline \multirow[t]{2}{*}{ Level of problem } & \multicolumn{2}{|c|}{ 20-30 Years } & \multicolumn{2}{|c|}{$30-40$ years } & \multicolumn{2}{|c|}{ Total } \\
\hline & $\mathbf{n}$ & $\%$ & $\mathbf{n}$ & $\%$ & $\mathbf{n}$ & $\%$ \\
\hline No Problem & 1 & 1.6 & 3 & 5 & 4 & 3.3 \\
\hline Low & 50 & 83.3 & 42 & 70 & 92 & 76.6 \\
\hline Moderate & 7 & 11.6 & 14 & 23.3 & 21 & 17.5 \\
\hline High & 2 & 3.3 & 1 & 1.6 & 3 & 2.5 \\
\hline Total & 60 & 100 & 60 & 100 & 120 & 100 \\
\hline
\end{tabular}

$\chi 2=5.28$, Table Value $=7.81, \alpha=0.05$, insignificant at $5 \%$

Results reveal that majority of the sample females had low (76.6\%) level of digestive problems. The females reported that they hardly suffered from high levels of the digestion related problems. Statistically there was no significant difference in the two age groups on the dimension of digestive problems. Once in a while they reported having problems such as diarrohea, constipation, acidity and stomach pain.

\section{Musculoskeletal System}

Table 5

Musculoskeletal System

\begin{tabular}{|c|c|c|c|c|c|c|}
\hline \multirow[t]{2}{*}{ Level of problem } & \multicolumn{2}{|c|}{ 20-30 Years } & \multicolumn{2}{|c|}{$30-40$ years } & \multicolumn{2}{|c|}{ Total } \\
\hline & $\mathbf{n}$ & $\%$ & $\mathbf{n}$ & $\%$ & $\mathbf{n}$ & $\%$ \\
\hline No Problem & 0 & 0 & 0 & 0 & 0 & 0 \\
\hline Low & 19 & 31.6 & 19 & 31.6 & 38 & 31.6 \\
\hline Moderate & 36 & 60 & 39 & 65 & 75 & 62.5 \\
\hline High & 5 & 8.3 & 2 & 3.3 & 6 & 5 \\
\hline Total & 60 & 100 & 60 & 100 & 120 & 100 \\
\hline
\end{tabular}


$\chi 2=1.42$, Table Value $=7.81, \alpha=0.05$, insignificant at $5 \%$.

Table 5 reveals that majority of the sample females reported having moderate $(62.5 \%)$ or low level of (31.6\%) musculoskeletal problems. Those who acknowledged having such problems reported suffering from joint pains, back pain, fatigue and weakness. Some of the women reported that when they had their monthly menstrual cycle they faced backache and pain in the pelvic region more frequently. Calculation of $\chi^{2}$ reveals insignificant differences in the musculoskeletal problems faced by women in the two age groups.

6.

Skin

\begin{tabular}{|c|c|c|c|c|c|c|}
\hline \multicolumn{7}{|c|}{$\begin{array}{c}\text { Table } 6 \\
\text { SKIN }\end{array}$} \\
\hline \multirow{2}{*}{ Level of problem } & \multicolumn{2}{|c|}{ 20-30 Years } & \multicolumn{2}{|c|}{ 30-40 years } & \multicolumn{2}{|c|}{ Total } \\
\hline & $\mathbf{n}$ & $\%$ & $\mathbf{n}$ & $\%$ & $\mathbf{n}$ & $\%$ \\
\hline No Problem & 5 & 8.3 & 3 & 5 & 8 & 6.6 \\
\hline Low & 17 & 28.3 & 27 & 45 & 44 & 36.6 \\
\hline Moderate & 26 & 43.3 & 19 & 31.6 & 45 & 37.5 \\
\hline High & 12 & 20 & 11 & 18.3 & 23 & 19.1 \\
\hline Total & 60 & 100 & 60 & 100 & 120 & 100 \\
\hline
\end{tabular}

$\chi 2=5.88$, Table Value $=7.81, \alpha=0.05$, insignificant at $5 \%$ level.

Table 6 reveals that majority of the sample $(37.51 \%)$ had moderate or low levels $(36.6 \%)$ of the skin problems. $19.1 \%$ females reported having high levels of skin problems. Dry cracked skin, boils, skin rashes, sun burns and lesions were the commonly encountered problems. Like else where here also statistically insignificant difference was noted in the skin problems faced by the two age groups.

\section{Nervous System}

Table 7

NERVOUS SYSTEM

\begin{tabular}{|c|c|c|c|c|c|c|}
\hline \multirow[t]{2}{*}{ Level of problem } & \multicolumn{2}{|c|}{ 20-30 Years } & \multicolumn{2}{|c|}{ 30-40 years } & \multicolumn{2}{|c|}{ Total } \\
\hline & $\mathbf{n}$ & $\%$ & $\mathbf{n}$ & $\%$ & $\mathbf{n}$ & $\%$ \\
\hline No Problem & 3 & 5 & 6 & 10 & 9 & 7.5 \\
\hline Low & 43 & 71.6 & 37 & 61.6 & 80 & 66.6 \\
\hline Moderate & 13 & 21.6 & 17 & 28.3 & 30 & 25 \\
\hline High & 1 & 1.6 & 0 & 0 & 1 & 0.8 \\
\hline Total & 60 & 100 & 60 & 100 & 120 & 100 \\
\hline
\end{tabular}

$\chi^{2}=9.06^{*}$, Table Value $=7.81, \alpha=0.05$, significant at $5 \%$ level.

Table 7 reveals that most of the female construction workers i.e., $66.6 \%$ had low levels of nervous system problem. Another $25 \%$ reported encountering moderate levels of nervous system related problems. The nervous system related problems encountered were fainting spells, bouts of giddiness, headaches and cold sweats. On this dimension of physical health there was significant difference between the two age groups. More $30-40$ year olds $(28.3 \%)$ had moderate levels of nervous system problems than the younger age group.

\section{Genitourinal System}

Table 8

Genitourinal System

\begin{tabular}{|c|c|c|c|c|c|c|}
\hline \multirow{2}{*}{ Level of problem } & \multicolumn{2}{|c|}{ 20-30 Years } & \multicolumn{2}{|c|}{$30-40$ years } & \multicolumn{2}{|c|}{ Total } \\
\hline & $\mathbf{n}$ & $\%$ & $\mathbf{n}$ & $\%$ & $\mathbf{n}$ & $\%$ \\
\hline No Problem & 1 & 1.6 & 0 & 0 & 1 & 0.8 \\
\hline Low & 14 & 23.3 & 32 & 53.3 & 46 & 38.3 \\
\hline Moderate & 38 & 63.3 & 25 & 41.61 & 63 & 52.5 \\
\hline High & 7 & 11.6 & 3 & 5 & 10 & 8.3 \\
\hline Total & 60 & 100 & 60 & 100 & 120 & 100 \\
\hline
\end{tabular}

$\chi 2=8.8^{*}$, Table Value $=7.81, \alpha=0.05$, significant at $5 \%$ level.

Most of the females (52.5\%) reported facing moderate levels of genitourinal problems. The common problems encountered were pain and uneasiness during menstruation, pain and burning sensation during urination, white discharge, lack of bladder control etc. calculation of chi square reveal significant differences in the genitourinal problems faced by women in the two age groups. 


\section{9. $\quad$ Fatigability}

Table 9

Fatigability

\begin{tabular}{|c|c|c|c|c|c|c|}
\hline \multirow[t]{2}{*}{ Level of problem } & \multicolumn{2}{|c|}{ 20-30 Years } & \multicolumn{2}{|c|}{ 30-40 years } & \multicolumn{2}{|c|}{ Total } \\
\hline & $\mathbf{n}$ & $\%$ & $\mathbf{n}$ & $\%$ & $\mathbf{n}$ & $\%$ \\
\hline No Problem & 5 & 8.3 & 2 & 3.3 & 7 & 5.8 \\
\hline Low & 16 & 26.6 & 25 & 41.6 & 41 & 34.1 \\
\hline Moderate & 22 & 36.6 & 24 & 40 & 46 & 38.3 \\
\hline High & 17 & 28.3 & 9 & 15 & 26 & 21.6 \\
\hline Total & 60 & 100 & 60 & 100 & 120 & 100 \\
\hline
\end{tabular}

$\chi 2=7.71$, Table Value $=7.81, \alpha=0.05$, significant at $5 \%$ level.

Table 8 reveals that most of the female construction workers $(38.3 \%)$ had moderate or low level of fatigue $(34.1 \%)$. But $21.6 \%$ respondents had high levels of fatigue. These females felt tired and exhausted very easily and even after resting for sometimes they felt tired. They felt sick and uncomfortable especially when they worked for long duration at a stretch.

10. Illness

Table 10

ILLNESS

\begin{tabular}{|c|c|c|c|c|c|c|}
\hline \multirow[t]{2}{*}{ Level of problem } & \multicolumn{2}{|c|}{ 20-30 Years } & \multicolumn{2}{|c|}{ 30-40 years } & \multicolumn{2}{|c|}{ Total } \\
\hline & $\mathrm{n}$ & $\%$ & $\mathrm{n}$ & & $\mathbf{n}$ & $\%$ \\
\hline No Problem & 3 & 5 & 1 & 1.6 & 4 & 3.3 \\
\hline Low & 25 & 41.6 & 19 & 31.6 & 44 & 36.6 \\
\hline Moderate & 15 & 25 & 24 & 40 & 39 & 32.5 \\
\hline High & 10 & 16.6 & 23 & 38.3 & 33 & 27.5 \\
\hline Total & 60 & 100 & 60 & 100 & 120 & 100 \\
\hline
\end{tabular}

$\chi 2=9.05^{*}$, table value $=7.81, \alpha=0.05$, significant at $5 \%$ level

Table 10 reveals that majority of the sample females mentioned either having low incidence $(36.6 \%)$ or moderate incidence $(32.5 \%)$ of illness. But at the same time more than a quarter i.e., $27.5 \%$ females reported having high incidence of illness. Many of these females had suffered from malaria, measles, joint pains, anemia, fevers, colds and other similar problems. There were major differences in the illness levels of the two age groups. Older female construction workers faced comparatively higher level of illness than the younger age group.

\section{Summary}

Women inspite of being actively involved in construction work are often discounted of their presence and contribution. Construction industry in itself is a difficult work sector which is confronted with many occupational hazards, to add to this women's position is all the more deplorable. The unorganized nature of their work puts them at a higher risk both at the economic as well as at the health front. Based on the findings of the study it is inferred that the female construction workers by virtue of their living condition and especially their work condition tend to experience a number of physical problems. Since these women come from disadvantaged sections of the society and already suffer from varying degrees of under nutrition, along with this the harsh working conditions leave these women susceptible to many physical dangers and hazards.

It was found that majority of the sample females had moderate to high level of problems related to the eyes. Shah and Mehta (2009) had also reported that eye problems are commonest among construction workers. Watery eyes, pain and irritation was commonly reported and further, these problems were more common during summer season. Most females even though had low to moderate occurrence of respiration problems nonetheless, chest congestion and breathing disturbances were encountered by many of them. Allan et al (2009) had also reported incidences of respiration problems among construction workers. Suarthana et al (2007) had also reported that chest and breathing related problems are relatively common among construction workers. Also, majority of the sample had moderate to low level of musculo skeletal problems. Back pain, joint pains were commonly faced by these construction workers. These findings are supported by those of Valsangkar and Sai (2012); Ranjwan and Zend et al (2007). Skin problems also ranged from moderate to low in most cases. Studies by Adsul et al (2011) and Bock et al (2003) have detailed reference to the skin problems encountered by construction workers. As far as fatigue and illness was concerned, it was noted that it was usually in the low to moderate category. These construction workers mostly felt tried at work and had fell ill many times. Though the illness could be attributed to other factors as well yet the poor work environment could also aggravate their situation. Many of the women faced genitourinary problems which had specific reference to their menstrual ill 
health. However, cardio vascular problems, digestive problems and nervous system related problems were reported not to be very common among the sample female construction workers.

The results further highlight that it was usually the older construction workers who faced the physical health problems to higher level that the younger age group respondents. Statistically also there was significant difference between the health status of the two groups especially on dimensions of eyes, nervous system, genitourinal system and illness These point to the fact that the work environment did take a toll on the health of the construction workers.

There is an urgent need to appreciate the role of women in the construction sector. For long they have been used as a source of cheap labour by the males and hence their health and welfare was of little concern to anyone. Appropriate and viable strategies need to be developed to make the work environment of the construction workers safe. This occupation is indeed a dangerous one and therefore the health and safety of the workers is paramount. Utter neglect of the health and welfare of the construction workers has made this industry one of the most unsafe for its workers. The unhealthy and unsafe work environments need to be altered to bring at least some security to the people involved in it.

\section{References:}

[1]. Adsul, B.B., Laad, P.S., Howal, P.V. and Chatyrvedi, R.M. (2011). Health problems among migrant construction workers: A unique public-private partnership project. Indian Journal of Occupational and Environmental Medicine, 15 (1), 20-32.

[2]. Allan, M., Jones, H., and Mark, R. (2009). Inhalation rates for risk assessment involving construction workers in Canada. Human and Ecological Risk, 15 (2), 371-387.

[3]. Bock, M., Schmidt, A., Brunckne, T., and Diepgen, T.L. (2003). Occupational skin diseases in the construction industry. British Journal of Dermatology, 149(6), 1165-1171

[4]. Dong, X. (2005). Long work hours, work scheduling and work related injuries among construction workers in the United States. Scandavian Journal of Work, Environment and Health, 31, 329-335.

[5]. Gurav, R.B., Kartikeyan, S., Wayal, R., Joshi, S.D. (2005). Assessment of health profile of daily wage labourers. Indian Journal of Occupational Environmental Medicine, 9, 115-117.

[6]. Jhanvala, R. and Kanbur, R. (2002). Construction women workers as masons, Tamil Nadu, India. Journal of International Women's studies, $11(2), 121-141$.

[7]. Lahiri, T. (2012). By the numbers: Where Indian women work. The Wall Street Journal, Nov 14, 2012.

[8]. Shah, C.K. and Mehta, H. (2009). Study of injuries among construction workers in Ahmedabad city, Gujarat. Indian Journal of Practicing Doctor, 5 (6): 4-8.

[9]. Surathana, E., Moons, K.G., Heederik, D., Meijer, E. (2007). A simple disgonstic model for risking out pneumoconiosis among construction workers. Occupational Environmental Medicine, 64 (9), 595-601.

[10]. Ranjwan, S.R. and Zend, J.P. (2007). Helath status of women employed in unorganized band self employed sector. Journal of Dairying, Food and Home Scince, 26 (3), 402-431.

[11]. Valsangkar, S., and Sai, K.S. (2012). Impact of musculoskeletal disorders and social determinants on health in construction workers, 3 (3), 1727-1730 